\title{
Drug treatment of personality disorder
}

\author{
Peter Tyrer
}

For many involved in the management of people with personality disorders the title of this article may appear to be a contradiction; drugs may alter mental state but intrinsically seem unlikely to alter personality. Nevertheless, drugs are available for treating personality disorders (even though none of them are licensed for these conditions). So it is hardly surprising that there is now a considerable body of literature on the subject which has recently been extensively reviewed (Stein, 1992) but which has attracted more attention since personality disorders have achieved greater prominence in all parts of psychiatric practice. In reviewing this literature it is important to stress four basic requirements before any treatment can be regarded as effective in the personality disorders:

(a) The treatment should be effective in the pure form of the personality disorder (i.e. independent of comorbidity).

(b) Efficacy needs to be established using the classical methodology of the randomised controlled trial (despite inherent difficulties in using this methodology for personality disorders).

(c) Because there are no established drug treatments for personality disorder any treatment tested has to be superior in efficacy to a placebo pill using the methodology described in (b).

(d) It should show evidence of its efficacy over a period of at least six months in view of the long duration of personality disorder.

For none of the treatments described below have these four requirements all been satisfied. Evidence of efficacy is limited to date, and in this review a wider perspective will be taken to include evidence of improvement in patients who have comorbidity (i.e. dual diagnoses of mental state and personality disorders) and of suspected efficacy for drugs that have not as yet been tested with sufficient rigour in these disorders.

Because of the considerable degree of overlap between different personality disorders in both DSM-IV and ICD-10 classifications (another example of comorbidity) the personality disorders will be discussed in three major groupings or clusters: flamboyant personality disorder (including antisocial, narcissistic, histrionic and borderline); the eccentric personality disorders (paranoid and schizoid and schizotypal in the USA); and the anxious or fearful personality disorders (anankastic, dependent and anxious). These have now become accepted groups in the DSM literature (e.g. Reich \& Thompson, 1987) and a similar grouping is developing in the ICD10 classification which can be linked to severity of disorder (Tyrer \& Johnson, 1996).

\section{Domanial personality disorders - evidence of sufficient efficacy to justify tentative clinical use}

In this section the evidence of drug treatments in those diagnosed within the domain of personality disorders alone (hence the adjective domanial) will be discussed.

\section{Flamboyant personality disorders}

Almost all the evidence for the efficacy of drug treatment in the flamboyant personality disorders comes from one member of the group. borderline personality disorder, and as this condition includes affective and psychotic features among its current clinical criteria (DSM-IV) (i.e. by definition it is a heterogeneous disorder) it may not be the best exemplar of the group. The most thorough studies have been carried out by Soloff and his colleagues and these demonstrate that in the short-term low dose antipsychotic drugs such as haloperidol in dosages between 4 and $16 \mathrm{mg}$ daily (Soloff et al, 1986) is more effective than placebo and, perhaps surprisingly in view of the frequent incidence of depressed mood in this condition, also have some advantages over tricyclic antidepressants. However, in the longer term these benefits are not so clear. Drop-out rate on antipsychotic drugs is high and most of the therapeutic gains compared with placebo disappear after 16 weeks of therapy (Cornelius et al, 1993).

Antidepressants should not necessarily be regarded as ineffective in this group of conditions as review of the literature suggests that some patients may do particularly well as others do particularly badly (Stein, 1992; Soloff, 1994). 
Several published studies (all with small numbers of patients) have none the less created sufficient agreement to hint (in order of strength of evidence) that lithium therapy (Sheard, 1976; Links et al, 1990) and monoamine-oxidase inhibitors (MAOIs) such as phenelzine and tranylcypromine (Cowdry \& Gardner, 1988; Cornelius et al, 1993) and carbamazepine (Cowdry \& Gardner, 1988) have some efficacy in this condition. There is also evidence that fluoxetine and other selective serotonin reuptake inhibitors (SSRIs) may also be effective in borderline personality disorder; with one randomised trial by Salzman et al (1995) showing significant reduction in anger in patients treated with fluoxetine compared with placebo (although the sample of 22 was disappointingly small). The drugs in all these studies have been given for a short time only (16 weeks or less) with hints that any positive effects shown become less over time. There is general agreement that behaviour and symptoms associated with irritability, anger and impulsivity are helped most by the drug treatment, and that control of these symptoms may make the patient more amenable to other forms of therapeutic intervention (Soloff, 1994).

\section{Eccentric personality disorders}

In strict terms no drug treatment has been shown to be effective in this group of conditions. However, schizotypal personality disorder, which overlaps considerably with borderline personality disorder (George \& Soloff, 1986) and therefore complicates interpretation, also responds to lowdose neuroleptic drugs (Goldberg et al, 1986). A wide range of dosage was used for the antipsychotic drug, thiothixene $(5-40 \mathrm{mg})$ in this study but response was similar in both low and high dosage.

\section{Anxious and fearful personality disorders}

There is also difficulty in interpreting data from these personality disorders as a mood state, anxiety, predominates in this group, and this is also an integral part of the personality disorder. Beneficial effects of drugs, at least in the shortterm, may be a direct consequence of their effects on mood rather than on the personality disorder. There is also a problem of diagnostic overlap between some personality disorders and neurotic disorders, most marked between avoidant (anxious) personality disorder and social phobia (Herbert et al, 1992). Nevertheless, the general impression from the literature is that antidepressants in general have some value in treatment and are widely used. However, the evidence for efficacy is poor and includes only small studies (e.g. Deltito \& Stam, 1989).

\section{Comorbid personality and mental state disorders - evidence of sufficient efficacy to justify tentative clinical use}

Although it is even more difficult to decide whether or not drug treatment is effective in comorbid personality and mental state disorder, this combination of disorders is more common than domanial personality disorders in clinical practice (de Girolamo \& Reich, 1993) - and the clinician needs to have some guidelines on when. or sometimes more importantly, when not to treat, with psychotropic drugs. This can be discussed for the three main comorbid groups.

Flamboyant personality disorders and substance misuse and dependence

This is a dangerous combination with regard to drug treatment and is liable to lead to both abuse and overdoses of prescribed psychotropic drugs. The prescription of benzodiazepines is to be avoided in particular as in this population there are more likely to be paradoxical reactions, such as rage associated with other forms of angry behaviour. Lithium therapy may sometimes be helpful as there is good evidence that it is effective in reducing anger and impulsiveness in those with alcohol dependence (Merry et al, 1976), antisocial personality (Sheard et al, 1976) and learning disability (Tyrer et al, 1984). Because benzodiazepines are frequently used in the detoxification of alcohol dependence, particular care should be taken to ensure that prescription does not continue after the period of withdrawal has passed because of the dangers of later abuse.

\section{Schizophrenia and flamboyant personality disorders}

The association between schizophrenia and flamboyant personality disorders (particularly the impulsive and dissocial groups) is common. As the treatment of both schizophrenia and flamboyant personality disorder can include antipsychotic drugs in high or low dosage, it is reasonable to use them in appropriate dosage in this clinical situation (although interpretation of the reasons for improvement is difficult). What is important is to extend the dosage range for such patients with comorbid diagnoses; a dose of, for instance, $20 \mathrm{mg}$ of flupenthixol decanoate every four weeks, may be effective in this group although such a dose is normally considered to be too low.

\section{Anxious personality disorder and neurotic disorders}

This condition, which can be termed the general neurotic syndrome (Tyrer, 1985) suggests that the core elements of neurosis are a combination of anxious (and to some extent depressive) 
symptoms and a dependence towards obsessional personality disorder. Again in this group it is probably wise to avoid benzodiazepines because of the danger of dependence, and there is evidence that withdrawal syndromes are more severe in such patients when the benzodiazepine is withdrawn (Tyrer et al, 1983; Murphy \& Tyrer, 1991). It is preferable to use antidepressants under such circumstances. There is some evidence that the tricyclic antidepressants are superior to the MAOIs when both personality disorder and mental state disorder are present (Shawcross \& Tyrer, 1985) and this is reinforced by evidence that antidepressants such as dothiepin, are better than psychological treatments in patients with both neurotic and personality disorder in the long-term (two years) compared with those with neurotic disorder alone, who fare better with psychological treatments (Tyrer et al, 1993). However, these effects are only apparent after several months of treatment and are not so prominent in the acute phase (Shea et al, 1990).

\section{Summary}

The null hypothesis that drug treatment of personality disorder is inappropriate has not yet been disproved. The evidence suggests that it may be a useful aid to treatment but the definitive studies that show that any benefit is independent of mental state effects have not been done. Most of the efficacy evidence comes from studies of the borderline group in which mental state and personality features are concurrent. However, knowledge of additional morbidity of a personality disorder may affect the treatment of a mental state disorder, including the choice of drug treatment. In summary, one can only concur with the views of Klar \& Siever (1984) 14 years ago, that the drug treatment of these conditions "remains a clouded area governed more by opinion than fact". Our current drug treatment of personality disorder is like following a badly marked track through a dense fog - you can see only a very short distance ahead but are grateful for any guidance going.

\section{References}

Corneluus, J. R., SOloff, P. H., PERel, J. M., et al (1993) Continuation pharmacotherapy of borderline personality disorder with haloperidol and phenelzine. American Journal of Psychiatry. 160, 1843-1848.

COWDRY, R. W. \& GARDNER. D. L. (1988) Pharmacotherapy of borderline personality disorder: alprazolam. carbamazepine, trifluoperazine and tranylcypromine. Archives of General Psychiatry. 45. 111-119.

DE GiRolamo, G. \& REICH, J. H. (1993) Personality Disorders. Geneva: World Health Organization.

DeltrTo, J. A. \& STAM, M. (1989) Psychopharmacological treatment of avoidant personality disorder. Comprehensive Psychiatry, 30, 498-504.

George, A. \& SOLOFF, P. H. (1986) Schizotypal symptoms in patients with borderline personality disorders. American Journal of Psychiatry, 143, 212-215.
Goldberg, S. C., Shulz. S. C.. Shulz, P. M., et al (1986) Borderline and schizotypal personality disorders treated with low dose thiothixene versus placebo. Archives of General Psychiatry, 43, 680-686.

HERBERT, J. D., HOPE, D. A. \& BELLACK, A. S. (1992) Validity of the distinction between generalized social phobia and avoidant personality disorder. Journal of Abnormal Psychology, 101, 332-339.

KLAR, H. \& SIEVER, L. J. (1984) The psychopharmacologic treatment of personality disorders. Psychiatric Clinics of North America, 7, 791-801.

LINKS. P. S., STEINER, M., BOIAGo, I., et al (1990) Lithium therapy for borderline patients: preliminary findings. Journal of Personality Disorders, 4, 173-181.

MERRY, J., REYNOLDS, C. M., BAILEY, J., et al (1976) Prophylactic treatment of alcoholism by lithium carbonate. Lancet, th, 481-482.

MURPHY, S. M. \& TYRER. P. (1991) A double-blind comparison of the effects of gradual withdrawal of lorazepam. diazepam and bromazepam in benzodiazepine dependence. British Journal of Psychiatry, 158, 511-516.

REICH, J. \& THOMPSON, W. D. (1987) DSM-III personality disorder clusters in three generations. British Journal of Psychiatry, 160, 471-475.

Salzman, C., Wolfson, A. N., SchatzBerg, A., et al (1995) Effect of fluoxetine on anger in symptomatic volunteers with borderline personality disorder. Journal of Clinical Psychopharmacology, 16, 23-29.

SHAWCROSS, C. R. \& TYRER, P. (1985) Influence of personality on response to monoamine oxddase inhibitors and tricyclic antidepressants. Journal of Psychiatric Research, 19, 557-562.

Shea, M. T., PIlkons, P. A., Beckham. E., et al (1990) Personality disorders and treatment outcome in the NIMH treatment of depression collaborative research program. American Journal of Psychiatry. 147, 711-718.

SHEARD, M. H.. MARINI. J. L.. BRIDGES. C. I.. et al (1976) The effect of lithium on impulsive aggressive behavior in man. American Journal of Psychiatry. 133, 1409-1413.

SoLOFF, P. H. (1994) Is there any drug treatment of choice for the borderline patient? Acta Psychiatrica Scandinavica, 89 (suppl. 379), 50-55.

Soloff, P. H., GeORGe, A., NATHAN, R. S., et al (1986) Progress in pharmacotherapy of personality disorders: a double blind study of amitriptyline, haloperidol and placebo. Archives of General Psychiatry. 48, 691-697.

STEIN, G. S. (1992) Drug treatment of the personality disorders. British Journal of Psychiatry. 161, 167-184.

TYRER. P. (1985) Neurosis divisible? Lancet, $L$, 685-688.

- \& JoHnson. T. (1996) Establishing the severity of personality disorder. American Journal of Psychiatry. 163, 1593-1597.

- . OWEN, R. \& DAwLINGS, S. (1983) Gradual withdrawal of diazepam after long-term therapy. Lancet, $i, 1402-1406$.

- . Sievewright, N, Ferguson. B., et al (1993) The Nottingham Study of Neurotic Disorder: effect of personality status on response to drug treatment, cognitive therapy and self-help over two years. British Journal of Psychiatry. 162, 219-226.

TYRER, S. P.. WALSH, A., EDWARDS, D. E., et al (1984) Factors associated with a good response to lithium in aggressive mentally handicapped subjects. Progress in Neuropsychopharmacology and Biological Psychiatry. 8. 751-755.

Peter Tyrer, Professor of Community Psychiatry. Imperial College School of Medicine, Paterson Centre, London W2 1PD 